\title{
IMPLEMENTASI ALAT PERMAINAN EDUKATIF MAHASISWA KKN-PPM UNIVERSITAS PGRI ADI BUANA SURABAYA DI DESA BULANG PRAMBON SIDOARJO
}

\author{
Martha Suhardiyah', Veni Anggreni², Siti Munawaro ${ }^{3}$, Endah Wahyu Anasukha ${ }^{4}$, Miftakhul Jannah ${ }^{5}$, \\ Nungky Suharwati ${ }^{6}$, Hardiyani Eka Putri ${ }^{7}$, Indra Kurniawan ${ }^{8}$, Diah Rizkianah ${ }^{9}$, Harnanik $^{10}$ \\ ${ }^{1}$ Fakultas Ekonomi, Universitas PGRI Adi Buana Surabaya, \\ 2, 3, 4, 5, 8, 9, 10 Fakultas Keguruan Ilmu Pedidikan, Universitas PGRI Adi Buana Surabaya, \\ ${ }^{6,7}$ Fakultas Teknik, Universitas PGRI Adi Buana Surabaya \\ Email: ${ }^{2}$ inevvenianggreni@gmail.com
}

\begin{abstract}
APE is one of the programs that are of interest and attention of the villagers Bulang. APE program's activities consist of three parts: Play Dough, Finger Painting and Puppet Gloves and Socks. Implementation of the 3 parts of APE division performed separately considering the target of three different divisions.Zainal (2013: 153) observation is a process of observation and recording systematically / sequence, logical, objective and rational about various phenomena that exist, both in the actual situation and in artificial situations to achieve certain goals. The method used observation to determine the level of appreciation of the PKK, teachers and children kindergarten / early childhood Bulang village. APE Program activities held on February 9 to 11, 2017. The target participants in the program are 66 participants. Sources of funds derived from the Student Contribution LPPM and corruption in 2017.
\end{abstract}

Keywords : finger painting, play dough and creativity

\section{PENDAHULUAN}

Undang-undang RI Nomor. 20 Tahun 2003 tentang sistem pendidikan nasional Bab 1 Ayat 14 menyatakan :

"Pendidikan anak usia dini adalah upaya pembinaan yang tujukan kepada anak sejak anak lahir sampai dengan usia enam tahun yang dilakukan melalui pemberian rangsangan pendidikan untuk membantu pertumbuhan dan perkembangan jasmani dan rohani agar anak memiliki kesiapan memasuki pendidikan lebih lanjut."

Anak usia dini memiliki kemampuan belajar yang luar biasa terutama pada masa kanak-kanak. Keingintahuan anak untuk belajar menjadikan anak kreatif dan eksploratif. Anak belajar dengan seluruh panca inderanya untuk memahami sesuatu dan dalam waktu yang singkat beralih ke hal lain untuk dipelajari. Karakteristik anak usia dini menjadi hal yang penting untuk dipahami agar memiliki generasi yang mampu mengembangkan diri secara optimal mengingat pentingnya usia emas (the golden age) tersebut. Mengembangkan kreativitas anak memerlukan peran penting pendidik. Anak kreatif memuaskan rasa keingintahuannya melalui berbagai cara seperti bereksplorasi, bereksperimen, dan banyak mengajukan pertanyaan kepada 2 orang lain. Namun kenyataannya masih banyak anak-anak yang memiliki kreativitas yang rendah. Keadaan tersebut disebabkan karena kurangnya pengembangan kreativitas sejak usia dini.

Kegiatan pembelajaran di TK dan PAUD "Kids Ceria" cenderung pada kegiatan mewarnai dan bernyanyi. Hal ini menyebabkan anak bosan dan cenderung bermain sendiri ketika kegiatan pembelajaran. Berdasarkan permasalahan tersebut, mahasiswa KKN memberikan pembelajaran yang berbeda dari kegiatan sebelumnya yaitu Finger Painting dan Play Dough. 
Finger Painting adalah kegiatan melukis dengan mengoleskan kanji yang diberi pewarna makanan pada karton atau kertas dengan media jari atau telapak tangan. Selain menggunakan media jari atau telapak tangan, dapat juga menggunakan alat makan seperti sendok dan garpu. Sedangkan Play Dough adalah adonan mainan yang terbuat dari tepung terigu.

Bermain Finger Painting, anak dapat mengenal warna, percampuran warna, dan melemaskan jari-jari. Sedangkan dengan bermain Play Dough, dapat bermanfaat dalam perkembangan berfikir anak, kemampuan sensorik (belajar tentang tekstur dan menciptakan sesuatu), dan kemampuan sosial anak.

Kreatif dan inovatif merupakan dambaan setiap orang tua terhadap anaknya. Namun, sangat jarang anak-anak zaman sekarang melakukan hal-hal positif yang berhubungan dengan ide atau gagasan mereka. Banyak anakanak yang lebih tertarik dengan permainan modern karena beberapa bahannya mengandung zat-zat berbahaya, selain itu anakanak bermain dengan gadget yang kurang mendidik sehingga membuat minat belajar menjadi turun.

APE adalah salah satu program yang diminati dan mendapat perhatian dari warga desa Bulang. Untuk kegiatan program APE tediri dari 3 bagian yaitu Play Dough, Finger Painting dan Boneka Sarung Tangan dan Kaos Kaki. Pelaksanaan 3 bagian dari divisi APE dilakukan secara terpisah mengingat target dari ketiga divisi tersebut berbeda.

Untuk Play Dough dan Finger Painting, targetnya adalah anak-anak PAUD dan TK. Pelaksanaan program tersebut dilaksanakan pada hari kamis tanggal 09 Februari 2017. Untuk pelaksanaannya, para mahasiswa anggota divisi dibantu dengan anggota KKN dan pihak PAUD dan TK mengajak para siswa PAUD dan TK untuk bermain sekaligus belajar menggunakan media Play Dough dan Finger Painting. Para siswa PAUD membuat gambar daun pada pohon menggunakan media One Finger Painting atau menggunakan satu jari tangan. Sedangkan untuk siswa TK, para anggota divisi dan KKN memberikan pengajaran menggunakan media Play Dough dan Finger Painting. Untuk Play Dough, siswa diajarkan membuat beberapa bentuk makanan dan hewan. Sedangkan untuk Finger Painting, para siswa diarahkan dan diajarkan untuk membuat berbagai jenis gambar seperti bunga, lollipop, kupu-kupu dan lain-lain sesuai dengan kreativitas siswa.

Untuk Boneka Sarung Tangan dan Kaos Kaki, targetnya adalah Ibu-ibu PKK dan guru PAUD. Program tersebut dilaksanakan pada hari sabtu tanggal 11 Februari 2017 bertempat di balai desa Bulang. Perwakilan dari divisi APE memberikan pengarahan secara langsung bagaimana cara membuat boneka dari sarung tangan dan kaos kaki. Para Ibu PKK menaruh perhatian yang besar dan antusias dalam mengikuti pengarahan yang diberikan oleh perwakilan divisi APE. Selain itu Ibu-ibu juga diajak untuk praktek secara langsung dalam pembuatan boneka sarung tangan dan kaos kaki. Ibu-ibu dipersilahkan untuk membawa pulang hasil karya yang sudah mereka buat dengan dibantu oleh divisi APE dan mahasiswa KKN.

Oleh karena itu, mahasiswa KKN membuat alternatif permainan yang mendidik bagi anak-anak di Desa Bulang yaitu, Program APE. Program APE adalah program pembuatan Alat Permainan Edukatif untuk membangun dan mengembangkan jiwa kreatif anak anak, remaja, serta ibu-ibu didesa Bulang, kecamatan Prambon, Sidoarjo. Program ini berupa Permainan seperti Boneka Sarung Tangan dan Kaos Kaki. Yang dapat diaplikasikan dalam kehidupan sehari-hari anak-anak dan alat permainan yang aman karena bahan yang digunakan tidak berbahaya selain itu ramah lingkungan. Tujuannya adalah Melatih masyarakat sekitar dalam menumbuh kembangkan kreatifitas dengan membuat keterampilan dengan bahan yang mudah didapat dan harga terjangkau.

\section{METODE}

\section{A. Metode Observasi}

Menurut Nasution (dalam Sugiyono, 2012:226) menyatakan bahwa observasi adalah dasar dari semua ilmu pengetahuan. Metode observasi adalah metode yang menggunakan cara pengamatan terhadap objek yang menjadi pusat perhatian pada penelitian (Muliawan, 2014:62).

Sedangkan menurut Zainal (2013:153) observasi adalah suatu proses pengamatan dan pencatatan secara sistematis/urut, logis, objektif, dan rasional mengenai berbagai fenomenafenomena yang ada, baik dalam situasi yang 
sebenarnya maupun dalam situasi buatan untuk mencapai tujuan tertentu.

Metode yang digunakan observasi untuk mengetahui tingkat apresiasi ibu-ibu PKK, guru dan anak-anak TK/PAUD desa Bulang.

\section{HASIL}

Kegiatan Program APE dilaksanakan pada tanggal 09-11 Februari 2017. Target peserta dalam program ini adalah 66 peserta. Sumber dana yang digunakan berasal dari LPPM dan Iuran Mahasiswa KKN 2017. Adapun rincian rencana dan jadwal kegiatan sebagai berikut :

1. Boneka kaos kaki dan sarung tangan yang dilakukan kepada ibu-ibu PKK di desa Bulang Kecamatan Prambon Kabupaten Sidoarjo sebagai pembekalan untuk menumbuhkan kreatifitas ibu-ibu, ibu-ibu sangat antusias mengikuti proses pembuatan boneka dari kaos kaki dan sarung tangan. Perasaan senang.

2. Play dought dilakukan pada peserta didik taman kanak-kanak berjalan dengan baik dan ceria, peserta didik sangat antusias mengikuti langkah pembuatan playdought serta berkreasi sesuai dengan imajinasinya dengan baik.

3. Finger painting yang dilakukan pada peserta didik taman kanak-kanak berjalan dengan baik, peserta didik antusias mengikuti langkah pembuatan Finger painting serta mempraktikan nya dengan baik. perasaan senang terlihat dari raut wajah peserta didik, karena mereka merasa senang dapat berkreatifitas sesuai dengan keinginannya. Kegiatan ini sangat melatih kemampuan anak dalam mengenal warna sehingga mereka dapat menggambarkan keinginannya sendiri sesuai kreatifitasnya.

\section{PEMBAHASAN}

Kegiatan program APE yang pertama yangdilaksanakan pada tanggal 09 Februari 2017.

\section{Play dought}

Dilakukan pada peserta didik taman kanakkanak kelas B berjalan dengan baik dan ceria, peserta didik sangat antusias mengikuti langkah pembuatan playdought serta berkreasi sesuai dengan imajinasinya dengan baik. Proses pembuatan Play dought yang dilakukan oleh peserta didik sendiri sehingga proses pembuatan terlaksana dengan seria. Setelah proses pembuatan slesai, pengaplikasian Play dought peserta didik sangan antusias dan mengeluarkan semua ide kreatifnya dalam membuat Play dought.

\section{Finger Painting}

Finger painting yang dilakukan pada peserta didik taman kanak-kanak kelas A berjalan dengan baik, peserta didik antusias mengikuti langkah pembuatan Finger painting serta mempraktikan nya dengan baik. perasaan senang terlihat dari raut wajah peserta didik, karena mereka merasa senang dapat berkreatifitas sesuai dengan keinginannya. Kegiatan ini sangat melatih kemampuan anak dalam mengenal warna sehingga mereka dapat menggambarkan keinginannya sendiri sesuai kreatifitasnya.

Proses pembuatan Finger Painting sangat antusias dilakukan oleh peserta didik, namun kami sarankan proses pembuatan Finger Painting harus didampingi oleh orang yang lebih dewasa dikarekanakan berhubungan dengan api dan kompor. Pengaplikasian juga berjalan dengan senang dan ceria, peserta didik dapat mengambarkan sesuai imajinasi mereka.

\section{Boneka kaos kaki dan sarung tangan}

Boneka kaos kaki dan sarung tangan yang dilakukan kepada ibu-ibu PKK di desa Bulang Kecamatan Prambon Kabupaten Sidoarjo sebagai pembekalan untuk menumbuhkan kreatifitas ibu-ibu, ibu-ibu sangat antusias mengikuti proses pembuatan boneka dari kaos kaki dan sarung tangan. Perasaan senang.Dalam proses pembuatan boneka ibu PKK sangat antusias mengikuti langkah-langkah pembuatan, sehingga proses berjalan dengan lancar.

\section{SIMPULAN}

Program Kerja Pokok APE mendapat kesimpulan bahwa program kerja:

1. Play Dought, yang dilaksanakan pada Peserta didik TK B berjalan dengan baik

2. Finger Painting yang dilaksanakan pada peserta didik TK A berjalan dengan baik.

3. Boneka Koas kaki dan Sarung tangan yang dilaksanakan pada ibu-ibu PKK berjalan 
dengan baik.

\section{SARAN}

APE atau dapat di katakan Alat Permainan Edkatif merupakan permainan yang dapat digunakan oleh anak-anak tanpa danya ganguan bahaya, untuk itu saran yang kami berikan, kepada masyarakat buatkanlah permainan untuk anak-anak anda yang tidak berbahaya bagi kesehatan, sehingga anak dapat bermain dengan sehat dan gembira.

DAFTAR PUSTAKA

Sugiyono. 2012. Metode Penelitian Kuantitatif Kualitatif Dan $R \& D$. Bandung: Alfabeta.

Zainal, Arifin. 2013. Evaluasi Pembelajaran. Bandung: PT Remaja Rosdakarya. 